JPKM, Vol.4, No.1, September 2018, Hal 109 - 118

DOI: http://doi.org/10.22146/jpkm.27512

ISSN 2460-9447 (print), ISSN 2541-5883 (online)

Tersedia online di http://jurnal.ugm.ac.id/jpkm

\title{
Penguatan Peran Warga Masyarakat dalam Perencanaan, Penganggaran, dan Evaluasi Hasil Pembangunan Desa
}

\author{
Susetiawan $^{1^{*}}$, DC. Mulyono ${ }^{2}$, dan Muh. Yunan Roniardian ${ }^{3}$ \\ ${ }^{1,2,3}$ Pusat Studi Pedesaan dan Kawasan UGM \\ "pspk_ugm@yahoo.com \\ Submisi: 15 Agustus 2017; Penerimaan: 13 Agustus 2018
}

\begin{abstract}
ABSTRAK
Undang-undang No. 6 Tahun 2014 mengamanatkan bahwa perencanaan pembangunan desa harus dilaksanakan secara partisipatif dan melibatkan seluruh masyarakat, termasuk kelompok rentan (minoritas, difabel, perempuan, dan miskin). Hal tersebut bertujuan agar pembangunan yang dilaksanakan oleh desa benar-benar bermanfaat bagi seluruh warga. Akan tetapi, hingga saat ini sebagian besar desa di Indonesia belum dapat melaksanakan amanat undang-undang tersebut. Hal ini terbukti dengan masih adanya desa yang melaksanakan perencanaan pembangunan secara elitis dan sepenuhnya dilakukan oleh pemerintah desa tanpa melibatkan masyarakat. Selain itu, ada pula desa yang sudah mencoba melibatkan masyarakat yakni melalui mekanisme "musrenbangdes", namun belum semua komponen masyarakat diundang dalam "musrenbangdes" tersebut. Dampak dari perencanaan pembangunan yang belum bersifat partisipatif adalah manfaat pembangunan desa belum bisa dirasakan oleh seluruh lapisan masyarakat, sehingga program pembangunan belum dapat disebut berhasil. Sebagai salah satu upaya untuk mewujudkan perencanaan pembangunan desa yang partisipatif, PSPK UGM mengadakan kegiatan pelatihan perencanaan, penganggaran, dan evaluasi hasil pembangunan desa di Desa Jomboran. Kegiatan tersebut melibatkan perwakilan dari semua komponen masyarakat desa (warga masyarakat, pengurus organisasi sosial, dan pemerintah desa). Melalui pelatihan ini, perencanaan pembangunan desa diharapkan akan dapat dilaksanakan secara partisipatif di masa yang akan datang, sehingga hasil-hasil pembangunan dapat dirasakan oleh seluruh warga.
\end{abstract}

Kata kunci: perencanaan partisipatif, pembangunan desa

\begin{abstract}
Law No. 6 of 2014 mandates that village development planning should be implemented in a participatory manner, involving all communities including vulnerable groups (minorities, disabled, women, poor). It is so that the development undertaken by the village really beneficial to all villagers in the village. However, to date, most villages in Indonesia are still unable to implement the mandate. There are villages that carry out elitist development planning, fully undertaken by the village administration without the involvement of the community. There are also villages that have tried to involve the community, through musrenbangdes mechanism, but unfortunately not all community components are invited in the musrenbangdes. The impact of development planning that has not been participatory is that village development can not be felt by all levels of society. Meanwhile, village development can not be said to succeed if there are
\end{abstract}


still some people who have not been able to feel the benefits. As one of the efforts to realize the participatory village development planning, PSPK UGM conducts training on planning, budgeting and evalauasi of village development results in Jomboran Village. The activity involves representatives from all components of the village community (community members, administrators of social organizations, and village government), and through this training it is hoped that in the future village development planning can be implemented in a participatory manner so that the results of the builders can be felt by all citizens.

Keywords: participatory planning, village development

\section{PENDAHULUAN}

Alasan Pusat Studi Pedesaan dan Kawasan (PSPK) Universitas Gadjah Mada melaksanakan kegiatan pengabdian dengan tema penguatan peran warga masyarakat dalam perencanaan, penganggaran, dan evaluasi hasil pembangunan desa adalah ditetapkannya UU No. 6 Tahun 2014 tentang Desa. Selain memberi kewenangan yang lebih luas kepada pemerintah desa untuk melaksanakan tugas pembangunan desa yang dibuktikan dengan kebijakan pengalokasian anggaran APBN untuk desa yang dari tahun ke tahun jumlahnya semakin meningkat, undang-undang tersebut juga mengamanatkan bahwa perencanaan pembangunan desa harus dilaksanakan secara partisipatif dan melibatkan seluruh masyarakat, termasuk kelompok rentan (minoritas, difabel, perempuan, miskin). Hal itu bertujuan agar pembangunan yang dilaksanakan oleh desa benar-benar bermanfaat bagi seluruh warga masyarakat, termasuk yang tergolong dalam kelompok rentan.

Kegiatan pengabdian yang dilaksanakan oleh PSPK UGM berlokasi di Desa Jomboran, Kecamatan Klaten Tengah, Kabupaten Klaten. Lokasi tersebut dipilih berdasarkan informasi yang diperoleh dari warga masyarakat Desa Jomboran bahwa desa tersebut belum dapat melaksanakan kegiatan perencanaan pembangunan secara partisipatif. Selama ini, kegiatan perencanaan pembangunan masih dilaksanakan secara elitis yang sepenuhnya dilaksanakan oleh kepala desa dan aparat pemerintah desa, serta belum melibatkan warga masyarakat khususnya kelompok rentan.

Dampak dari perencanaan pembangunan yang belum partisipatif di Desa Jomboran adalah manfaat pembangunan belum bisa dirasakan oleh seluruh lapisan masyarakat, padahal pelaksanaan pembangunan desa belum bisa disebut berhasil apabila masih ada sebagian warga masyarakat yang belum merasakan manfaat dari pelaksanaan pembangunan tersebut. Meskipun demikian, semua pihak berharap 
pelaksanaan pembangunan di Desa Jomboran bisa dirasakan manfaatnya oleh seluruh warga masyarakat dan tidak ada satu pun yang merasa terabaikan. Dengan demikian, cita-cita luhur para pendiri bangsa, yaitu terciptanya masyarakat yang sejahtera, adil, makmur, dan merata dapat segera terwujud.

Sebagai salah satu upaya untuk mewujudkan perencanaan pembangunan desa yang partisipatif, PSPK UGM mengajak semua warga masyarakat di Desa Jomboran beserta pemerintah desa (kepala desa, perangkat desa, dan BPD) untuk belajar bersamasama tentang perencanaan pembangunan desa yang partisipatif melalui kegiatan pelatihan perencanaan, penganggaran, dan evaluasi hasil pembangunan desa. Melalui kegiatan tersebut, perencanaan pembangunan desa yang akan dilaksanakan diharapkan bisa benar-benar sesuai dengan amanat undang-undang, sehingga hasil-hasil pembangun di desa tersebut bisa dirasakan manfaatnya oleh seluruh warga masyarakat.

\section{MASALAH}

Masalah dalam kegiatan pengabdian kepada masyarakat yang dilaksanakan di Desa Jomboran ini adalah perencanaan pembangunan desa yang masih bersifat elitis dan belum melibatkan semua komponen masyarakat desa.

\section{TUJUAN}

Tujuan dalam kegiatan pengabdian kepada masyarakat yang dilaksanakan di Desa Jomboran ini sebagai berikut:

a. Meningkatnya kesadaran warga masyarakat, termasuk kelompok rentan untuk ikut berpatisipasi dalam proses perencanaan, penganggaran, dan evaluasi hasil pembangunan desa sehingga hasil pembangunan tersebut benar-benar mencerminkan prinsip partisipatif, yaitu melibatkan seluruh warga masyarakat.

b. Meningkatnya kesadaran organisasi sosial kemasyarakatan (PKK, karang taruna, kelompok tani, P3A, dasawisma, dll.), organisasi sosial keagamaan ( majelis taklim, TPA, kelompok pengajian, dll.), dan institusi/pranata sosial (rembuk warga, pertemuan RT/RW, gotong royong, dll.) yang ada di Desa Jomboran untuk menjadi ajang pengorganisasian perencanaan, penganggaran, dan evaluasi hasil pembangunan desa. 
c. Meningkatnya kesadaran pemerintahan desa (pemerintah desa dan BPD) untuk lebih terbuka dan berani secara aktif menjaring aspirasi seluruh warga masyarakat, termasuk aspirasi dari kelompok rentan (minoritas, difabel, perempuan, dan miskin) sehingga perencanaan, penganggaran, dan evaluasi hasil pembangunan desa benar-benar bersifat partisipatif.

\section{KAJIAN PUSTAKA}

Menurut hasil penelitian Agustin et al. (2016), keberhasilan suatu program pembangunan bukan hanya berdasar pada kemampuan pemerintah, tetapi juga berkaitan dengan partisipasi masyarakat dalam menjalankan program pembangunan. Hal tersebut selaras dengan hasil penelitian yang telah dilakukan oleh Fadil et al. (2013) bahwa partisipasi masyarakat dalam pembangunan sangat berpengaruh pada keberhasilan pelaksanaan suatu program pembangunan. Menurut Elida Imro'atin et al. (2015), partisipasi masyarakat dalam pembangunan sangat penting karena partisipasi/keikut sertaan masyarakat tersebut akan menumbuhkan rasa memiliki terhadap proses pembangunan khususnya pelaksanaan program pembangunan di desa. Menurut Adisasmita, (2006:38) partisipasi masyarakat dapat didefenisikan sebagai keterlibatan dan pelibatan anggota masyarakat dalam pembangunan, meliputi kegiatan dalam perencanaan dan pelaksanaan (implementasi) program pembangunan. Adisasmita juga mengatakan peningkatan partisipasi masyarakat merupakan salah satu bentuk pemberdayaan masyarakat (social empowerment) secara aktif yang berorentasi pada pencapaian hasil pembangunan yang dilakukan dalam masyarakat pedesaan. Pemberdayaan masyarakat merupakan upaya pemanfaatan dan pengelolaan sumber daya masyarakat pedesaan secara lebih aktif dan efisien.

Soetrisno (1995:207) mendefinisikan partisipasi sebagai kemauan rakyat untuk mendukung secara mutlak program-program pemerintah yang ditentukan dan tujuannya oleh pemerintah. Dia juga menambahkan bahwa partisipasi adalah kerja sama antara rakyat dan pemerintah dalam merencanakan, melaksanakan, melestarikan, dan mengembangkan hasil pembangunan. Sementara itu, Mubyarto (1997:35) mendefinisikan partisipasi sebagai kesediaan untuk membantu keberhasilan setiap program sesuai dengan kemampuan setiap orang tanpa berarti mengorbankan 
kepentingan diri sendiri. Arimbi (1993:1) mendefinisikan partisipasi sebagai feedforward information and feedback information. Dengan definisi ini, partisipasi masyarakat sebagai proses komunikasi dua arah yang terus menerus dapat diartikan sebagai komunikasi antara pihak pemerintah sebagai pemegang kebijakan dan masyarakat di sisi lain sebagai pihak yang merasakan langsung dampak dari kebijakan tersebut.

Perencanaan adalah suatu proses mempersiapkan secara sistematis kegiatankegiatan yang akan dilakukan untuk mencapai suatu tujuan tertentu (Tjokromidjojo, 1998:12). Perencanaan pembangunan adalah suatu proses perumusan alternatifalternatif atau keputusan-keputusan yang didasarkan pada fakta-fakta yang akan digunakan sebagai bahan untuk melaksanakan suatu rangkaian kegiatan/aktivitas kemasyarakatan, baik yang bersifat fisik (material) maupun nonfisik (mental dan spiritual), dalam rangka mencapai tujuan yang lebih baik (Riyadi, 2005:7).

Desa menurut UU No. 6 tahun 2014 adalah kesatuan masyarakat hukum yang memiliki batas wilayah yang berwenang untuk mengatur dan mengurus urusan pemerintahan, kepentingan masyarakat setempat berdasarkan prakarsa masyarakat, hak asal usul, dan atau hak tradisional yang diakui dan dihormati dalam sistem pemerintahan Negara Kesatuan Republik Indonesia. Untuk mendapatkan dukungan dan partisipasi yang kuat dari masyarakat terhadap pembangunan desa, maka masyarakat harus dilibatkan dalam proses pengambilan keputusan termasuk pada tahapan perencanaan pembangunan desa. Dengan demikian diharapkan akan timbul suatu rasa tanggung jawab bersama seluruh masyarakat desa terhadap pembangunan di desanya. Namun, untuk bisa berpartisipasi dalam pembangunan, menurut Sari et al. (2016) masyarakat perlu memiliki pemahaman yang luas tentang pembangunan partisipatif, khususnya dalam aspek perencanaan. Pemahaman masyarakat terhadap partisipasi dalam perencanaan sangat diperlukan dalam pembangunan partisipatif karena pemahaman terhadap perencanaan dalam pembangunan partisipatif akan menimbulkan suatu kesadaran masyarakat betapa pentingnya partisipasi masyarakat. 


\section{METODE}

Kegiatan penguatan peran warga masyarakat, termasuk kelompok rentan dalam perencanaan, penganggaran, dan evaluasi hasil pembangunan desa dilaksanakan dengan metode partisipatif, yaitu melibatkan masyarakat dalam setiap kegiatan yang akan dilaksanakan. Adapun beberapa bentuk kegiatan yang telah dilaksanakan dalam program ini adalah (a) pelatihan peningkatan pemahaman tentang UU Desa; (b) pelatihan perencanaan pembangunan desa; (c) pelatihan penganggaran pembangunan desa; dan simulasi penyusunan perencanaan pembangunan desa yang lebih bersifat partisipatif. Kegiatan pelatihan tersebut diperuntukkan bagi:

a. perwakilan warga masyarakat, termasuk kelompok rentan (perempuan, miskin, difabel, dan minoritas);

b. perwakilan pengurus organisiasi sosial/organisasi kemasyarakatan (PKK, Karang Taruna, Dasa Wisma);

c. perwakilan pengurus organisasi sosial keagamaan (kelompok pengajian, majelis taklim, TPA, kelompok gereja);

d. perwakilan pengurus organisasi sosial ekonomi (kelompok tani, P3A); dan

e. perwakilan pemerintahan desa (aparat pemerintah desa dan anggota BPD, anggota tim 11).

Untuk menunjang kelancaran kegiatan tersebut, tim pelaksana mengundang para narasumber yang memiliki kompetensi di bidang perencanaan pembangunan desa secara partisipatif, baik yang bergelar profesor, doktor, maupun master.

\section{HASIL DAN PEMBAHASAN}

Dalam kurun waktu tujuh bulan masa pelaksanaan kegiatan pengabdian, tim PSPK UGM telah melaksanakan kegiatan pelatihan dan simulasi terkait dengan perencanaan, penganggaran, dan evaluasi hasil pembangunan desa. Informasi detail tentang pelaksanaan kegiatan disajikan dalam Tabel 1 berikut ini.

Pelaksanaan kegiatan pelatihan peningkatan pemahaman terkait dengan UU Desa. Pelatihan ini dilaksanakan pada Mei 2017 dan dihadiri oleh perwakilan warga masyarakat, perwakilan pengurus organisasi sosial/keagamaan/ekonomi, dan perwakilan pemerintah desa. Narasumber dalam pelatihan ini adalah Bapak Zunaji Zamroni, M.A., 
aktivis pemberdayaan masyarakat desa, khususnya terkait dengan perencanaan pembangunan desa.

Tabel 1 Pelaksanaan Kegiataan Pelatihan dan Simulasi Perencanaan, Penganggaran, dan Evaluasi Hasil Pembangunan di Desa Jomboran

\begin{tabular}{|c|c|c|c|}
\hline No. & Jenis Kegiatan & Peserta & $\begin{array}{c}\text { Waktu } \\
\text { Pelaksanaan }\end{array}$ \\
\hline 1. & $\begin{array}{l}\text { Pelatihan peningkatan } \\
\text { pemahaman terkait } \\
\text { dengan UU Desa }\end{array}$ & $\begin{array}{ll}\text { - } & \text { perwakilan warga masyarakat } \\
\text { - } & \text { perwakilan pengurus organisasi sosial } \\
\text { kemasyarakatan/keagamaan/ekonomi } \\
\text { - }\end{array}$ & Mei 2017 \\
\hline 2. & $\begin{array}{l}\text { Pelatihan perencanaan } \\
\text { pembangunan desa }\end{array}$ & $\begin{array}{ll}\text { - } & \text { perwakilan warga masyarakat } \\
\text { - } & \text { perwakilan pengurus organisasi sosial } \\
\text { kemasyarakatan/keagamaan/ekonomi } \\
\text { - } & \text { perwakilan pemerintah desa }\end{array}$ & Juni 2017 \\
\hline 3. & $\begin{array}{l}\text { Pelatihan } \\
\text { penganggaran } \\
\text { pembangunan desa }\end{array}$ & $\begin{array}{l}\text { - perwakilan warga masyarakat } \\
\text { - perwakilan pengurus organisasi sosial } \\
\text { kemasyarakatan/keagamaan/ekonomi } \\
\text { - perwakilan pemerintah desa }\end{array}$ & Juli 2017 \\
\hline 4. & $\begin{array}{l}\text { Simulasi penyusunan } \\
\text { perencanaan } \\
\text { pembangunan desa } \\
\text { secara partisipatif }\end{array}$ & $\begin{array}{l}\text { - perwakilan warga masyarakat } \\
\text { - perwakilan pengurus organisasi sosial } \\
\text { kemasyarakatan/keagamaan/ekonomi } \\
\text { - } \text { perwakilan pemerintah desa }\end{array}$ & $\begin{array}{l}\text { Agustus } \\
2017\end{array}$ \\
\hline
\end{tabular}

Sumber: Data primer diolah, Desa Jomboran, 2017

Pelaksanaan kegiatan pelatihan perencanaan pembangunan desa. Pelatihan ini dilaksanakan pada Juni 2017 dan dihadiri oleh perwakilan warga masyarakat, perwakilan pengurus organisasi sosial/keagamaan/ekonomi, dan perwakilan pemerintah desa. Narasumber dalam pelatihan ini adalah Ibu Dina Mariana, M.A., aktivis pemberdayaan masyarakat desa, khususnya terkait dengan perencanaan pembangunan desa.

Pelatihan dilaksanakan pada Juli 2017 dan dihadiri oleh perwakilan warga masyarakat, perwakilan pengurus organisasi sosial/keagamaan/ekonomi, dan perwakilan pemerintah desa. Narasumber dalam pelatihan ini adalah Bapak Sukasmanto, M.Si., aktivis pemberdayaan masyarakat desa, khususnya terkait dengan masalah penganggaran pembangunan desa.

Pelaksanaan kegiatan simulasi penyusunan counter draft APBDes dilaksanakan pada Agustus 2017 dan dihadiri oleh perwakilan warga masyarakat, perwakilan 
pengurus organisasi sosial/keagamaan/ekonomi, dan perwakilan pemerintah desa. Narasumber dalam pelatihan ini adalah Ibu Dina Mariana, M.A. dan Bapak Sukasmanto, M.Si., aktivis-aktivis pemberdayaan masyarakat desa, khususnya terkait dengan perencanaan dan penganggaran pembangunan desa.

Ada beberapa indikator yang digunakan untuk melihat terjadinya peningkatan kesadaran warga masyarakat, pengurus organisasi, dan aparat pemerintah desa dalam perencanaan, penganggaran, dan evaluasi hasil pembangunan desa. Beberapa indikator tersebut sebagai berikut.

a. Terbangunnya komitmen warga masyarakat untuk berani menyampaikan ide/usulan pada forum publik/musyawarah desa, khususnya dalam hal perencanaan, penganggaran, dan evaluasi hasil pembangunan.

b. Terbangunnya komitmen organisasi warga untuk mulai mempraktikkan dan mendiskusikan tata cara perencanaan, penganggaran, dan evaluasi hasil pembangunan dengan prosedur yang baik.

c. Terbangunnya komitmen aparat pemerintahan desa untuk terbuka, responsif, dan akuntabel dalam perencanaan, penganggaran, dan evaluasi hasil pembangunan desa.

Untuk mengukur tingkat keberhasilan kegiatan pelatihan dalam membangun komitmen warga masyarakat, komitmen pengurus organisasi sosial warga, serta komitmen aparat pemerintahan desa dalam perencanaan, penganggaran, dan evaluasi hasil pembangunan desa yang lebih partisipatif, setelah pelaksanaan kegiatan pelatihan diadakan survei terhadap para peserta pelatihan. Hasil survei dapat dilihat pada Tabel 2 berikut ini.

Berdasarkan data dalam tabel 2 di atas diketahui bahwa setelah mengikuti pelatihan perencanaan, penganggaran, dan evaluasi hasil pembangunan desa, sebagian besar responden $(96,6 \%)$ menyatakan berkomitmen untuk ikut berpartisipasi aktif dalam perencanaan, penganggaran, dan evaluasi hasil pembangunan desa. Berdasarkan kategori peserta, seluruh peserta $(100 \%)$ dari perwakilan pengurus organisasi sosial kemasyarakatan/keagamaan/ekonomi dan dari perwakilan pemerintahan desa menyatakan berkomitmen untuk berpartisipasi aktif dalam perencanaan, penganggaran, dan evaluasi hasil pembangunan desa. Adapun sebanyak 90\% kelompok perwakilan 
warga masyarakat berkomitmen untuk berpartisipasi aktif dalam perencanaan, penganggaran, dan evaluasi hasil pembangunan desa, sedangkan sisanya (10\%) menyatakan tidak memiliki komitmen untuk berpartisipasi aktif dalam perencanaan, penganggaran, dan evaluasi hasil pembangunan desa.

Tabel 2 Hasil Survei Terkait Komitmen untuk Terlibat dalam Perencanaan Pembangunan Desa

\begin{tabular}{clccc}
\hline No & \multicolumn{1}{c}{ Kelompok Peserta Pelatihan } & Jumlah & \multicolumn{2}{c}{$\begin{array}{c}\text { Hasil Survei (\%) } \\
\text { (komitmen) }\end{array}$} \\
\cline { 3 - 5 } & $\begin{array}{l}\text { Ya } \\
\text { Perwakilan warga masyarakat, termasuk } \\
\text { kelompok rentan } \\
\text { (perempuan/miskin/difabel/minoritas) }\end{array}$ & 20 & 90 & 10 \\
2. & $\begin{array}{l}\text { Perwakilan pengurus organisasi sosial } \\
\text { kemasyarakatan/keagamaan/ekonomi } \\
\text { (RT/RW/PKK/Karang Taruna/Takmir }\end{array}$ & 20 & 100 & 0 \\
$\begin{array}{l}\text { Masjid/Kelompok Pengajian, Kelompok } \\
\text { Tani/Peternak/Perajin) } \\
\text { Perwakilan pemerintah desa (kepala } \\
\text { desa/aparat desa/BPD/tim 11) } \\
\text { Total }\end{array}$ & 20 & 100 & 0 \\
\hline
\end{tabular}

Sumber: Data primer diolah, Desa Jomboran, 2017

Instrumen lain yang digunakan untuk mengukur komitmen warga masyarakat, pengurus organisasi sosial warga, dan pemerintah desa dalam perencanaan, penganggaran, dan evaluasi hasil pembangunan desa yang lebih partisipatif adalah counter draft rencana pembangunan desa (RAPBDes) yang disusun secara partisipatif. Dalam counter draft rencana pembangunan desa tersebut telah terakomodasi kepentingan warga masyarakat yang tergolong dalam kelompok rentan (miskin, difabel, perempuan, minoritas). Hal itu dibuktikan dengan adanya rencana program kegiatan yang langsung menyasar pada kelompok masyarakat tersebut.

\section{SIMPULAN}

Kegiatan penguatan peran serta warga masyarakat, termasuk kelompok rentan dalam perencanaan, penganggaran, dan evaluasi hasil pembangunan desa di Desa Jomboran berjalan dengan lancar dan baik. Kegiatan tersebut banyak memberi manfaat kepada warga masyarakat yang mengikuti pelatihan karena selama ini mereka belum pernah mengikuti kegiatan serupa. Kegiatan pelatihan juga berpengaruh pada 
peningkatan komitmen para peserta guna berpartisipasi aktif dalam perencanaan, penganggaran, dan evaluasi hasil pembangunan desa sehingga perencanaan pembangunan dapat dilakukan secara partisipatif sesuai amanat undang-undang. Memperhatikan beberapa hal baik tersebut, maka kegiatan penguatan peran serta warga masyarakat termasuk kelompok rentan dalam perencanaan, penganggaran, dan evaluasi hasil pembangunan desa perlu dilakukan di seluruh desa di Indonesia sehingga perencanaan pembangunan dapat dilakukan secara partisipatif.

\section{DAFTAR PUSTAKA}

Adisasmita, Raharjo. 2006. “Pembangunan Pedesaan Dan Perkotaan”. Yogyakarta: Graha Ilmu

Agustin, Merry et al. 2016. "Partisipasi Masyarakat Dalam Perencanaan Pembangunan Desa Melalui Musrenbang (Studi Kasus Pada Pembangunan Japordes Desa Tunggunjangkir Kecamatan Mantup Kabupaten Lamongan). Dalam Publika vol.4, no 1.

Arimbi, Mas Achmad. 1993. "Peran Serta Masyarakat dalam Pengelolaan Lingkungan”. Jakarta: Walhi.

Fadil, Fathurrahman et al. 2013. "Partisipasi Masyarakat Dalam Musyawarah Perencanaan Pembangunan di Kelurahan Kotabaru Tengah". Dalam Jurnal Ilmu Politik dan Pemerintahan Lokal, Volume II Edisi 2.

Mubyarto. 1997. "Gerakan Nasional Penanggulangan Kemiskinan, Kajian Bersama Pengembangan Kebijaksanaan”. Yogyakarta: Aditya Media.

Nur Laily, Elida Imro'atin et al. 2015. "Partisipasi Masyarakat Dalam Perencanaan Pembangunan Partisipatif'. Jurnal Kebijakan dan Manajemen Publik, volume 3, nomor 2

Riyadi \& Deddy. 2005 “Perencanaan Pembangunan Daerah”. Jakarta: PT Gramedia Pustaka Utama.

Sari, Ita Puspita et al. 2016. "Implementasi Pembangunan Partisipatif”. Jurnal Ekonomi (JE) Vol. 1 (1).

Soetrisno, Lukman. 1995. “Menuju Masyarakat Partisipatif”. Yogyakarta: Kanisius.

Tjokromidjojo, Bintoro. 1998. "Perencanaan Pembangunan". Jakarta: CV Haji Masagung. 